\title{
Memória, relatos e práticas de espaço: cidades em áreas de ocupação recente na Amazônia (Mato Grosso, 1970-2000)*
}

\author{
Regina Beatriz Guimarães Neto**
}

\section{O tema e o objeto: deslocamentos metodológicos}

Fazer história é antes de tudo realizar escolhas: selecionar documentos, instituir problemáticas, adotar escritas possíveis, em que o texto se apresente "[...] como um tecido de palavras, imagens e significados" (Calvino, 1993, p. 251). A escrita como construção propriamente dita da história é o coroamento do ofício do historiador, praticada nas diversas fases de seu trabalho, como uma arte de composição do resultado das investigações realizadas. No âmbito dessas reflexões, considera-se que a prática historiográfica atual procura romper, por um lado, com as barreiras erigidas pelos critérios de cientificidade que o modelo positivista apregoa, impondo o reinado do documento escrito e oficial; por outro, afasta-se cada vez mais da idéia de que a produção do conhecimento histórico prescinde de uma estrutura narrativa, em razão da premissa de que para ser ciência ou ter um estatuto científico, a história deveria funcionar segundo leis, cifras, série de números, controladas por meios técnicos (Le Goff, 1990). ${ }^{1}$

* Este artigo recebeu preciosas contribuições de João Carlos Barrozo (UFMT) e Antônio Torres Montenegro (UFPE). Agradeço a eles de forma especial.

** Professora da Universidade Federal de Mato Grosso e do Programa de Pós-Graduação da Universidade Federal de Pernambuco.

1 Ver também a crítica de P. Ricoeur em A bistória e a narrativa (1994, 133-320). 
As figuras de linguagem e os procedimentos próprios da narração são constituidores/produtores de inteligibilidade do texto escrito, reunindo e significando os múltiplos eventos passados na tessitura da trama, ${ }^{2}$ salientando sempre o diálogo entre as questões propostas e as pesquisas documentais.

A emergência de novos temas e modos de escrita da história, enfatizando-se sua dimensão narrativa, trouxe estratégias de abordagens bastante inovadoras, valorizando determinados registros que eram considerados de menor valor, como os relatos orais, ${ }^{3}$ as imagens fotográficas, a literatura de cordel, entre outros. Uma das questões mais importantes, nessa perspectiva, encontra-se na relevância que se pode dar à experiência dos atores sociais, destacando-se as trajetórias individuais e de grupos - imersas em contextos sociais múltiplos e de formas variáveis - que, do ponto de vista micro-histórico, são observadas em um universo complexo de negociações e apropriações em todos os níveis, como sugerem diversos autores que trilham os caminhos dessa metodologia (Levi, 2000; Revel, 1998; Vainfas, 2002).

Neste artigo procuro refletir acerca das abordagens teóricas e metodológicas, fundamentais para as investigações que desenvolvo acerca da história de algumas cidades de Mato Grosso, destacando-se aquelas localizadas na parte nordeste do estado - território do Araguaia -, Vila Rica e Confresa, nos limites com o estado do Pará. Privilegio certos aspectos que se constituem fios condutores para o estudo das práticas sociais e culturais dessas cidades, oferecendo, ainda, um dos acessos possíveis à compreensão do movimento de ocupação e reterritorialização do espaço amazônico, nas três últimas décadas do século XX e inícios do século XXI. A pesquisa inicia com uma interrogação acerca da relação entre a memória e as práticas dos habitantes dessas cidades e comunidades vizinhas; procura perceber que tal relação engendra relatos acerca das suas experiências vivenciadas em um tempo e espaço específicos, de combates e luta pela terra, em que o passado e o presente aparecem tecidos nas urdiduras das rememorações. ${ }^{4}$ Desde logo, coloca-se no centro das atenções a vida das

2 O destaque a esta questão ganha maior relevo nas análises desenvolvidas por Paul Ricoeur em Tempo e narrativa (1994). Ver também do mesmo autor: La mémoire, l'bistoire, l'oubli (2000).

3 Para a análise sobre a metodologia do uso das fontes orais ver especialmente a contribuição de Ferreira e Amado (1996); Montenegro (1994) e (2006); Alberti (1990).

4 Esta pesquisa é desenvolvida com apoio de uma bolsa de Produtividade do CNPq. 
pessoas e grupos sociais que para lá se dirigiram, marcadas pelas experiências dos deslocamentos migratórios. São enormes distâncias territoriais percorridas, tanto nas rotas do Sul para o Norte do Brasil, como também do Nordeste, do Sudeste e mesmo na circularidade dos caminhos inscritos nos eixos rodoviários do território amazônico.

Situada no âmago da problemática historiográfica, a questão central, nesse texto, é operacionalizar alguns deslocamentos metodológicos fundamentais. O primeiro a considerar é que as abordagens macro-históricas, fartamente utilizadas para os estudos sobre a Amazônia, dão a tônica às análises acerca do sistema capitalista globalizado ou o seu domínio, que não pára de se ramificar, enquadrando e transformando toda a arquitetura econômica, social e política da região. Ora, o movimento social deve ser visto de maneira mais complexa e contraditória, gerando inúmeras resistências, segundo o jogo das múltiplas apropriações culturais que se dão por meio de formas diferenciadas, dependendo dos indivíduos, das comunidades sociais e dos grupos étnicos.

A proposta que defendo privilegia as experiências miúdas e cotidianas, centradas em iniciativas individuais e mesmo coletivas, que se inscrevem em contextos variados. Nesse âmbito, as práticas sociais e culturais aparecem relacionadas às estratégias, as negociações e aos combates. Isto é, os grupos sociais enfrentam os grandes proprietários e, inúmeras vezes, a polícia do próprio estado, mas também estabelecem alianças com outros setores, como a Igreja Católica, os sindicatos e o ministério público em um complexo movimento tático, sinuosamente construído no contrapasso dos adversários. As pesquisas que focalizam o território amazônico parecem ter dado uma importância exorbitante ao jogo das estruturas e ao padrão de produção capitalista, centrado no modelo de crescimento econômico. Estas abordagens privilegiam processos sociais maciços, em que, mesmo dando-se relevância às diversas categorias de trabalhadores rurais e relacionando-as às áreas produtoras de agronegócios (pecuária, lavoura, indústria) e de mineração, ainda assim, as análises deduzem e compreendem os conflitos e as resistências, submetidos a uma forte lógica mecanicista do operar social.

Não quero com isso propugnar uma liberdade de ação dos atores, desconsiderando as regras normativas a que se encontram submetidos. Pelo contrário, tendo em vista esse universo poliédrico - território amazônico - as histórias narradas, ao transitarem pelas experiências dos 
personagens e grupos focalizados, levando-se em conta os fragmentos de relatos orais e escritos, tornam-se indicadoras de comportamentos e atitudes de homens e mulheres, que anunciam suas escolhas no imbricado jogo das redes sociais. Nestas, aparecem estabelecendo negociações importantes que direcionam suas vidas, sem que isto implique necessariamente uma ruptura com os sistemas normativos mais gerais.

A prática histórica postulada, nesse aspecto, não rejeita a análise do conjunto da sociedade, mas interessa-se pela situação vivida pelos agentes sociais, identificando as estratégias e táticas utilizadas, as imagens e símbolos que acionam conscientemente ou não (Revel, 1998, p. 15-38). Esta abordagem visa recuperar variáveis sociais e culturais mais complexas, agregando às investigações um grande número de fatores, acontecimentos, situações vivenciadas, desafios e enfrentamentos. Levando-se em conta a afirmação de J. Revel, ao introduzir as reflexões sobre a microhistória, com base em C. Ginzburg e C. Poni, observa que:

[...] a escolha do individual não é vista aqui como contraditória à do social: ela deve tornar possível uma abordagem diferente deste, ao acompanhar o fio de um destino particular - de um homem, de um grupo de homens - e, com ele, a multiplicidade dos espaços e dos tempos, a meada das relações nas quais ele se inscreve. (Idem, p. 21)

É esse também o procedimento adotado por Giovanni Levi (1992), que se posicionando contrário a determinados modos de explicação por demais abstratos, toma uma situação particular para averiguar as interações entre indivíduos, famílias e comunidades, tipos de negociações e as relações destas com o poder estatal, através dos aspectos mais diversificados da experiência social. Já Carlo Ginzburg traça o paradigma indiciário - focalizando situações excepcionais - colocando o historiador na trilha do investigador policial (1989), dialogando com as estruturas quase invisíveis. Por outro lado, as análises que priorizam as determinações mais gerais ou as estruturas totalizantes perderiam a riqueza que a complexidade das tramas e personagens podem oferecer. Contudo, as abordagens mais circunscritas aos recortes específicos dos objetos em questão não desconsideram relevar as condições históricas mais gerais, em que se encontram homens e mulheres que compartilham uma dada experiência 
social, e as situações em que discursos e comportamentos adquirem significados. Assim, a advertência de Jacques Le Goff, situada em um campo de reflexões que direciona outras perspectivas historiográficas, tornase muito importante:

Não se trata de modo algum de explicar o fenómeno em questão através destas condições históricas, de invocar uma causalidade histórica pura, e nisto deve consistir a modéstia da actuação histórica. Mas também esta actuação pretende recusar a validade de qualquer explicação e de toda prática que negligenciasse estas condições históricas. (Le Goff, 1984, p. 244)

Da mesma forma, além da compreensão das condições históricas, há também que se considerar o lugar da produção intelectual do texto, o qual orienta e conduz os passos dos investigadores, pressupondo-se que há um não-dito na base de sua formação. Os historiadores, dessa forma, tendem a buscar, com mais rigor, os legados interiorizados (Chartier, $1990)^{5}$ e as reflexões que levam a considerar as matrizes de discursos e de práticas sociais (Certeau, 1982). É por isso que, diante dos problemas levantados pela diversidade da documentação e das questões propostas, entende-se que os procedimentos metodológicos que orientam a produção dos objetos históricos, utilizando as mais variadas fontes, tornam necessárias determinadas escolhas - dentre uma multiplicidade de caminhos - que explicitam as regras próprias do fazer historiográfico.

Há um segundo deslocamento que proponho para a análise das práticas sociais e culturais, focalizando ou destacando os espaços de ocupação recente na Amazônia, sobretudo no estudo acerca das cidades que surgiram no âmbito das políticas governamentais. Deve-se acentuar que estas políticas seguiram diretrizes que orientaram o "povoamento dos espaços vazios" - conforme o discurso oficial do governo e dos empresários - com os denominados projetos de colonização. Deste modo, torna-se importante restringir o campo de análise e procurar produzir inteligibilidade tomando por base fragmentos muito significativos, apreendidos na vida social. Isto é, as investigações privilegiam pequenos acontecimentos,

5 Cf. especialmente a introdução, o primeiro e segundo capítulos. 
situações vividas, conflitos e iniciativas de seus habitantes, jogos de negociações, enfrentamentos e combates diversos que se podem captar nos inúmeros relatos de homens e mulheres. Estes, são os atores que fazem parte dos segmentos sociais que se mudaram - num movimento migratório intenso - para as áreas "destinadas à ocupação", na maior parte das vezes, sobrepostas a terras indígenas e de posses mais antigas. Na mesma trilha, as histórias narradas também possibilitam analisar as representações que as novas cidades adquirem e irrompem nos vários relatos e registros dos seus habitantes. O interesse, nesse sentido, é dar maior relevância às narrativas de espaço que assinalam práticas culturais constitutivas das configurações urbanas, como também aquelas que descrevem conflitos e apontam os lugares de combate e resistência, no território da cidade ou da zona de ocupação.

Deste modo, torna-se possível analisar as memórias que se entrelaçam aos espaços habitados, demarcados num intenso processo de reterritorialização; e, ainda, compor uma cartografia da experiência social que se delineia num desenho vivo e se expande na linguagem daqueles que se transformam nos atores sociais mais importantes da Amazônia.

\section{Territórios e histórias entrelaçadas: Vila Rica e Confresa}

Estudar as cidades que resultaram das políticas governamentais de distribuição de terras, associadas às estratégias de controle e ocupação do espaço amazônico, nas últimas décadas do século XX é como estar diante de um tabuleiro desenhado com mil cores e formas. Cada pequena parte tem suas histórias e memórias, assim como suas territorialidades configuradas e em constante transformação. É premente analisar o que se constitui como memória do passado, informando as percepções do presente e do futuro. No centro dessas percepções, encontram-se as histórias entrelaçadas de combate pela posse da terra, em que agricultores e outros segmentos de trabalhadores enfrentaram o poderio de grandes empresas agropecuárias, na parte nordeste de Mato Grosso. Empresas que se apropriaram da maior parte das terras disponíveis e as transformaram em grandes fazendas, onde predominam o agronegócio da soja, do algodão, do milho e da cana para a produção do álcool. Além das áreas destinadas à pecuária, à mineração, e à exploração da madeira. 
A parte norte de Mato Grosso, cortada pelas BR - 163, de Cuiabá a Santarém, e a BR - 158, que percorre toda a área do Araguaia, tendo como ponto de partida a cidade de Barra do Garças em direção ao estado do Pará, guarda uma memória de violência ou mais propriamente de violação dos direitos do trabalhador, constituindo-se em um espaço geográfico de constantes denúncias de trabalho degradante e/ou mesmo escravo. Ariovaldo Umbelino de Oliveira (1997), estudando os mecanismos de formação e as estratégias montadas para o estabelecimento dos projetos agropecuários em Mato Grosso, afirma:

Com a chegada dos grandes fazendeiros do Centro Sul, a partir da década de 60, e com as políticas públicas da SUDAM, a região se tornou um verdadeiro "barril de pólvora", com a presença de inúmeros conflitos entre índios, posseiros e os grileiros de terras.

Por meio de políticas governamentais (federais e estaduais) que incentivaram a ocupação dirigida, loteando grandes áreas de terras, Mato Grosso destacou-se também em razão dos projetos de colonização da iniciativa privada. ${ }^{6}$ A parte norte deste estado acabou se transformando no espaço por excelência de atuação das empresas colonizadoras do país, que adquiriam as nomeadas terras devolutas do Estado. Tais empresas se beneficiaram dos programas de incentivos fiscais e créditos subsidiados por meio da SUDAM; estenderam-se e apropriaram-se de áreas indígenas ${ }^{7}$ e de camponeses, incorporando, assim, grandes extensões de terras às áreas originalmente adquiridas "legalmente" do governo federal. O campo do "legalmente constituído" pode ser desmontado quando se investiga e vêm à tona as pressões políticas, os compadrios e as alianças entre empresários e políticos, tanto no nível estadual quanto nacional; os pagamentos de valores irrisórios em licitações viciadas, os departamentos de terras corruptos, as fraudes em cartórios, compras de documentos, grilagens e tantas outras práticas ilícitas (Cf. Moreno, 2007).

6 Ver sobre o tema da colonização recente em Mato Grosso: Oliveira, 1982; Guimarães Neto, 2002; Souza, 2001; Santos, 1993.

7 Os povos indígenas que mais sofreram com o avanço das fazendas e colonizadoras foram, especialmente, os Tapirapé, Karajá e Xavante. 
Os núcleos urbanos, originários dos projetos destinados à colonização, distribuídos espacialmente ao longo das grandes rodovias federais, além das atividades agrícolas, da pecuária e agroindustriais, envolveramse também com a exploração da madeira e mineração. Estes núcleos atraíram um grande grupo de migrantes e acabaram apresentando os maiores índices de crescimento populacional no estado. Estas áreas foram transformadas em cidades, mas também, desse movimento migratório, surgiram vilas, assentamentos do INCRA, acampamentos de "sem terras", entre tantas outras formas de ocupação do espaço amazônico. Devese assinalar que este é um território marcado pelas ações de grandes mineradoras, madeireiras, agroindústrias, agropecuárias, envolvidas com o agronegócio, e, muitas vezes, praticando o "trabalho escravo" - imobilização de trabalhadores à força - nas propriedades rurais, no corte da cana-de-açúcar, nas áreas de desmatamentos, e outras, alvo de constantes denúncias, como registra e denuncia a CPT (Comissão Pastoral da Terra) e várias entidades governamentais e não governamentais.

As disputas pela posse da terra na parte nordeste de Mato Grosso, que abrange o Araguaia, encontram-se registradas na história de lavradores, posseiros e demais trabalhadores sem terra, como ainda na história da Prelazia de São Félix do Araguaia, salientando-se a figura combativa do bispo católico Pedro Casaldáliga. ${ }^{8}$ Dois projetos de colonização privada, aprovados pelo INCRA no final da década de 70, destacaram-se neste território: o de Vila Rica e Confresa. ${ }^{9}$ Núcleos que tiveram as suas áreas de loteamento planejadas para receberem colonos do Sul do Brasil, influenciados pelas propagandas, que apresentavam estas terras como de muita fartura, com inúmeras possibilidades de trabalho e de progresso. Além disso, os agricultores do Sul, ao migrarem, foram nomeados de colonos e anunciados como os "novos bandeirantes" - homens e mulheres que estariam participando da construção de um "Brasil grande" -, recurso

8 O Arquivo da Prelazia de São Félix guarda documentos preciosos acerca da luta pela terra na região do Araguaia e a importância de Pedro Casaldáliga e de outros padres que com ele se envolveram diretamente na defesa dos direitos dos povoados e comunidades e de pessoas que sofriam a arbitrariedade de poderosos grupos de proprietários armados; o Jornal Alvorada, da Prelazia, continua a prestar importantes informações sobre a luta pela defesa dos direitos humanos e a atualizar uma memória histórica da violência (ver www. prelaziasaofelixdoaraguaia.org.br).

9 Deve-se citar, ainda, os projetos de colonização de Canarana e Água Boa que foram executados pelo grupo de Norberto Schwantes, com agricultores/colonos de Tenente Portela, RS. 
imagético muito utilizado pelo regime militar. De fato, as propagandas que valorizavam a "saga dos colonos" constituíram-se em importante estratégia do governo e das empresas, empenhadas em produzir uma imagem positiva desse grande movimento de trabalhadores em direção às áreas de colonização, na Amazônia (Cf. Guimarães Neto, 2003).

Focalizando o núcleo de colonização de Vila Rica, este foi aprovado pelo INCRA em finais da década de 70, em razão de uma subdivisão entre os sócios de uma grande agropecuária, denominada SERVAP (Serviços Auxiliares de Agropecuária), de Minas Gerais, que, como tal, já havia sido contemplada com os incentivos financeiros da SUDAM. Depois, quando parte da agropecuária se transforma na Colonizadora Vila Rica Ltda, passa a receber novos financiamentos do governo para fazer o loteamento de terras, tendo em vista o projeto de colonização, apresentando-se como um negócio muito rentável (superposição de projetos/financiamentos). Nesse sentido, o que antes era área para o gado passou a ser direcionada para a venda de terras aos pequenos proprietários empobrecidos do Sul. Os relatos dos colonos que vivenciaram a experiência dos primeiros tempos do projeto de colonização são reveladores de uma memória marcada pela paisagem dos espaços geográficos cobertos pelo capim colonião, imensas áreas de pastagens.

Os agricultores/colonos ao chegarem a essas áreas descobriam que tudo estava por construir, desde as estradas no meio da floresta, até os equipamentos sociais para uma vida coletiva. A sede da escola é emblemática nesse sentido, pois apresenta uma arquitetura ímpar, que conta um pouco dessa história: foi erguida sobre o antigo - e ainda muito recente espaço do curral para o gado da fazenda. Os relatos orais de pessoas que participaram da abertura da área para ocuparem os lotes vendidos a título de colonização atestam a precariedade absoluta das condições de habitabilidade. Nestas, as pessoas não tinham acesso sequer aos seus lotes, tendo tudo que ser construído pelas famílias, sobretudo os homens. Muitos irão falecer na derrubada da floresta (a motoserra é vista como uma "máquina de fazer viúvas"), tornando-se esta uma das memórias marcantes desse período. As famílias ao chegarem de cidades do Sul, mas também, do Sudeste, Centro-Oeste e Nordeste, após longas viagens em cima de caminhões, eram deixadas no centro dos núcleos dos projetos, cercados pela floresta. Para se protegerem da chuva e do sol, espalhavam uma lona de encerado sobre alguns troncos de árvores; quando conseguiam abrir 
espaços para construírem os primeiros barracos tinham que armar estratégias de proteção contra animais selvagens, como a onça e o porco-espinho. ${ }^{10}$

\section{Confresa: a cidade ocupada}

O caso da cidade de Confresa é singular. A empresa colonizadora Confresa, formada com base em três grandes agropecuárias (Codeara, Frenova e Sapeva), criou o projeto Tapiraguaia (uma junção dos nomes do povo indígena Tapirapé e rio Araguaia), planejado também para acolher os colonos do Sul. Esta área, que resultou na criação da cidade de Confresa, configurava um território de passagem e de entrecruzamento de diversas categorias de trabalhadores: posseiros já estabelecidos na região do Araguaia, desde as primeiras décadas do século XX, bem como, trabalhadores rurais sem terra que haviam se deslocado de várias partes do Brasil em busca de terra e trabalho. Eram homens e mulheres que acompanhavam os anúncios das empresas e notícias diversas (de uma rede de familiares e conhecidos, mas também de jornais), acerca das diversas frentes de trabalho, no setor da mineração, da exploração da madeira, nas fazendas agropecuárias e agroindústrias (como a Destilaria Gameleira) ou, ainda, para as áreas de colonização. No que tange a Destilaria Gameleira, situada próxima ao núcleo urbano de Confresa, esta empresa foi responsável por deslocar uma quantidade muito grande de trabalhadores do Nordeste, particularmente do Maranhão, contratados para o corte da cana-de-açúcar.

É necessário enfatizar que este território do Araguaia, onde se localiza Confresa, encontrava-se sob a influência e domínio das grandes fazendas agropecuárias como Codeara, Porto Velho, Tapirapé, Piraguaçu, Frenova, Sapeva, Agroselva. Para melhor investigar as relações de poder

10 Consultar os trabalhos de monografias de final de curso dos alunos de história (que também foram personagens dessas histórias), Projeto Parceladas da Universidade Federal de Mato Grosso (UNEMAT). Em especial: Ângela Maria Martini, Carla Báo, Maria do Espírito Santo Carneiro Kaefer, Maria Figueira Cerqueira e Ivone Terezinha Quinhones Zortea, que desenvolveram seus trabalhos sobre minha orientação. Arquivo do campus da Unemat de Luciara- MT. Ver também as monografias de Marinez Irene Folador Rech, tanto da graduação, como agora da especialização que se encerra neste ano de 2007, que, com muita competência, estuda o papel das mulheres na colonização de Vila Rica MT, de 1970 até 1990, também sob minha orientação. 
instauradas nesse espaço, analisar o controle sobre a vida e os destino dos trabalhadores e avaliar o poder de mando das grandes fazendas - em aliança com o Estado, na década de 1970 -, deve-se estudar as práticas e modos de agir característicos dos grupos empresariais envolvidos. O caso da Codeara (Companhia de Desenvolvimento do Araguaia), de propriedade do grupo Banco de Crédito Nacional-BCN, é muito esclarecedor. ${ }^{11}$

Esta fazenda reivindicava o direito de propriedade de uma área de 200.000 hectares ao norte do rio Tapirapé, na região do Araguaia, que incluía até mesmo o povoado de Santa Terezinha, fundado ainda na década de 1920 (depois elevado a condição de município, na década de 1980, onde se situaram as terras de Confresa). Diante da disputa de terra que se estabeleceu com posseiros e moradores de Santa Teresinha, foi criado um clima de terror no povoado e o conflito foi instalado. A polícia, o governo do estado e os pistoleiros da empresa invadiram o povoado e os posseiros reagiram, muitos foram presos, destacando-se a figura do padre Jentel que, mais tarde, foi expulso do Brasil, em 1975. ${ }^{12}$ A luta dos posseiros continuou, até que foi desapropriada uma pequena área para a criação do distrito, ao mesmo tempo em que o poder público se viu forçado a conceder mais uma extensão de terra a 120 posseiros (titulados com 100 ha.). Nesse espaço do conflito é que outras agropecuárias também atuaram.

Assim é que a Agropecuária Nova Amazônia S/A (FRENOVA) encenou novos conflitos, agora no povoado de Porto Alegre do Norte (que hoje faz divisa com o município de Confresa). A Frenova, interessada em assenhorear-se rapidamente das terras, como eles anunciavam, "limpando a área" (uma expressão que se referia às pessoas indesejáveis), preocupados com os posseiros e outros trabalhadores rurais que já se encontravam naquele espaço, chegou a dividir o povoado de Porto Alegre do Norte ao meio, com arames farpados; ${ }^{13}$ uma parte para ela, Frenova, e outra para a empresa Sapeva. Após longas disputas, resistências e mortes, além do abandono da posse por parte de muitos posseiros, que foram embora, desalojados de suas terras, Porto Alegre do Norte teve sua emancipação efetuada em 1986.

11 O conflito no Araguaia envolvendo a CODEARA foi amplamente estudado por Esterci (1987).

12 Cf. Martins (1979).

13 Maria do Rosário Soares Lima fez um rico estudo acerca da história de Porto Alegre do Norte (2002). 
Neste território de acirrada disputa pela terra é que a empresa Confresa implantou seu projeto de colonização. Contudo, envolvida em diversas falcatruas com a aquisição de terras, revendendo áreas já ocupadas, cobrando valores diferentes dos acordados, subindo cada vez mais o preço, e não atendendo as necessidades básicas dos agricultores-colonos, a empresa viu as terras, que dizia ser proprietária, acabarem paulatinamente conquistadas e ocupadas por posseiros, pequenos proprietários e trabalhadores diversos:

Foi indo, foi indo, até que inventaram fazer uma invasão. A mata que era reserva foi toda para o beleléu, aqui tinha gente de todos os lugares, deu gente de todo jeito, até o próprio gaúcho invadiu lote. Teve um velho que invadiu uma quadra inteira, cercou e depois, invadiram a quadra dele também. (Entrevista realizada por Maria Figueira Cerqueira com o senhor V.C.C., que preferiu não ser identificado, em Confresa, 04/01/2001)

O certo é que a empresa, ao cobrar um alto valor pela terra e o preço tornando-se inacessível para lavradores, posseiros e outras categorias de trabalhadores, criou uma situação insustentável para os ocupantes, já que haviam se deslocado de outras partes do país para adquirirem lotes em áreas de colonização e/ou muitos deles, perdido suas terras, seja com endividamentos com os bancos credores, seja expulsos da terra. O movimento migratório nos anos finais da década de 70 e por toda a década de 80, avançando pelos anos 90, foi intenso, sobretudo de pessoas e grupos que já se encontravam em território de Mato Grosso e estados vizinhos, como Pará, Tocantins e Goiás, seguindo os caminhos abertos pelas rodovias federais. Mas, sobretudo, deve-se considerar a tradição de luta e combate dos posseiros e outras categorias de trabalhadores rurais e urbanos sem terra, nesse território do Araguaia.

Apreende-se, de fato, uma aprendizagem de enfrentamento, práticas na ordem da luta, matando e morrendo, inventando estratégias de combate contra as poderosas fazendas, e levando com astúcia a sua resistência e poder pelo seu direito a terra. Nesse sentido, a força da Prelazia de São Félix do Araguaia foi fundamental, denunciando, procurando meios legais e sustentando com as comunidades o direito de se estabelecerem na terra (Casaldáliga, 1971). Houve toda uma educação envolvida 
com as práticas de mutirões, construção de espaços para escolas, atividades agrícolas conjuntas, entre outras iniciativas.

O conflituoso processo de reterritorialização e construção desses espaços, marcados pela intensa movimentação de trabalhadores rurais e urbanos, resultou no crescimento de inúmeras cidades, em Mato Grosso. ${ }^{14}$ Pelos dados do IBGE, Confresa e Vila Rica apresentam, nos dias de hoje, uma população com mais de 20 mil habitantes. Contudo, sob o manto do alardeado progresso, há sangue, tortura, trabalho escravo e muita pressão dos grupos sociais pelo acesso a terra. Deste modo, a área coberta pelo Araguaia viu crescer vários projetos de assentamento, em que, ao ler os relatórios do INCRA, acerca das informações que constam nos projetos, aparecem claramente palavras que expressam a prioridade à desapropriação das áreas que apresentam "grandes conflitos com assassinatos".

Confresa é um dos municípios de Mato Grosso que hoje possui uma das mais altas concentrações de comunidades oriundas de projetos de assentamentos de reforma agrária, regularizados pelo INCRA, obedecendo as políticas nacionais implantadas em meados da década de $1980 .{ }^{15}$ Contudo, cabe salientar que as áreas/pólos de assentamento não só no município de Confresa, mas em Mato Grosso como um todo, foram resultado, antes de pensar em qualquer proposta política de reforma agrária, de pressões sociais tendo em vista os graves conflitos por terra neste estado, muitos deles armados. Segundo Ferreira, Fernández e Silva (1999) pode-se dizer que:

[...] este número de assentados e assentamentos é uma resposta política dos governos estadual e federal às investidas dos movimentos de trabalhadores rurais sem terra e às lutas localizadas dos movimentos autônomos pela terra que, em Mato Grosso especificamente, multiplicam-se através de acampamentos rurais.

14 Considerando as duas últimas décadas do século XX, foram criados em Mato Grosso mais de cem municípios novos (Fonte do IBGE).

15 Os assentamentos existentes enquadram-se no âmbito das políticas do Plano Nacional de Reforma Agrária (PNRA) que orientaram o Plano Regional de Reforma Agrária (PRRA/Mato Grosso), em meados da década de 1980, que tiveram como objetivo controlar o quadro de tensão social e violência no campo, envolvendo posseiros, parceiros, e diversos tipos de trabalhadores temporários do campo, além de outras categorias sociais. Ver Ferreira, Fernández e Silva (1999). 
No jornal Alvorada, da Prelazia de São Félix do Araguaia, anunciando as mudanças e o crescimento da região do Norte-Araguaia, destacase o que chamam de "o atual mapa da região", com o seguinte registro:

O regional Confresa é uma das áreas que mais cresceu. [...] Há uma cidade, Confresa, 8 vilas (São José do Fontoura, 3 Flechas, Pé de Caju, Jacaré Valente, Novo Planalto, Canta Galo, Belo Horizonte, Lumiar) 33 comunidades rurais, 1 indústria, "a destilaria Gameleira", que se encontra na chamada lista suja do Ministério do Trabalho, por ter nela trabalhadores em situação análoga à escravidão; uma fazenda "Bridão Brasileiro" que está em conflito pela disputa pela posse da terra, tendo parado o processo administrativo de desapropriação, e a área indígena Urubu Branco, do povo Tapirapé. (Nov/Dez de 2006, n²60)

Com base nestas informações, pode-se ter uma noção aproximada da complexidade desse território: a diversidade étnica e cultural, os enfrentamentos políticos pelo acesso e direito a terra, a existência de práticas de trabalho escravo, entre as mais importantes. As oito vilas assinaladas pelo Jornal Alvorada foram resultantes dos Projetos de Assentamentos, conhecidos como PAs. Num espaço onde predominavam violentos confrontos, estas áreas foram disputadas pelos trabalhadores pela posse da terra com pistoleiros ou jagunços que guardavam as grandes propriedades, sobretudo as agropecuárias. A história deste combate pela terra pode ser vislumbrada em diversos acontecimentos. O de Canta Galo, localizado à margem da BR - 158, é exemplar.

\section{Canta Galo: linhas de convergência, linhas de fuga}

A ocupação da área que viria a constituir o PA Canta Galo foi iniciada nos últimos anos da década de 1980 por lavradores e demais trabalhadores sem terra vindos do Pará, Tocantins, Rondônia e do próprio estado de Mato Grosso (atestando um deslocamento constante no espaço amazônico), mas também de outras partes do Brasil, como Minas Gerais e estados do Nordeste. As terras eram consideradas de propriedade de José Carlos Pires Carneiro, Silvana Carraro Carneiro, José Carlos Augusto Lei- 
te Medeiros, proprietário dos cartórios Medeiros de São Paulo, e Maria Lucia Medeiros (ligados ao grupo das fazendas que originaram Confresa). Contudo, os espaços territoriais de Confresa e áreas adjacentes foram sendo ocupados, ${ }^{16} \mathrm{com}$ as pessoas tomando posse, conquistando e demarcando seus lotes, "fazendo outros mapas, mudando o rumo da cidade" (Cerqueira, 2002).

O senhor Alderino Alves Pereira foi um dos que buscou terra na área que se tornou o P.A Canta Galo. Indagado sobre as razões que o levou a ocupar terra na área em disputa, respondeu:

A necessidade da gente possuir uma terra, fazer um plantio, ter coisas pra comer, fartura na casa e lutar pela vida, né? [...] Quando escutava algum barulho de carro nós entrava na moita, com medo dos pistoleiros. ${ }^{17}$

Este tempo difícil e tenso é relatado pelo senhor Messias Pereira Fernandes, marcando o período da ocupação:

Cada dia que passava, mais intensa a perseguição ficava, a proprietária botou três pistoleiros para olhar a terra, todo dia vinha da Frenova e passava aqui, olhando a terra, botou gente pra andar de pé com a changa nas costas.

Vários relatos explicitam como a experiência da ocupação se tornava perigosa, dando conta dos propósitos declarados dos proprietários, como indica Sebastião do Véu: "Aí entrou a polícia com os pistoleiros e tirou todo mundo daqui." Osvaldo Pires complementa:

Uai, ela - uma das proprietárias - botou a policia para nos tirar daqui, e nós saia e fomos despejados em Porto Alegre, largaram nós no meio da rua.

16 Quase todos os projetos de assentamento do Araguaia resultaram de ocupações dos agricultores sem terra. Sobretudo em Confresa, o INCRA fez um processo de reconhecimento de uma situação de fato - legalizando e oficializando os assentamentos.

17 As entrevistas citadas, que relatam acerca da ocupação do Projeto de Assentamento Canta Galo e os conflitos decorrentes, foram realizadas por Marcos Ramos França, no período de abril a julho de 2004, para sua monografia como trabalho final do curso de História, sob minha orientação, no campus avançado de Confresa, Projeto Parceladas da Universidade Federal de Mato Grosso (UNEMAT). 
Alderino Alves ainda relata sobre um dos momentos mais difíceis em que se encontrou sob a ameaça dos pistoleiros:

Eram quatro pistoleiros, mas nós estava com 16 meninos, com a mulher e 16 meninos. O pistoleiro veio onde eu estava arrumando os trem, engatilhou a carabina em mim e disse: - arruma ligeiro! Eu disse: - não meu amigo, não é do jeito que você está pensando!

Estes poucos registros são fragmentos muito significativos, por um lado, das práticas dos fazendeiros para "limpar a área", como diziam, e, por outro, da forma como os posseiros enfrentavam a situação que se lhes apresentava. O fato de o senhor Alderino se encontrar rodeado de crianças e mulheres denota uma tática muito utilizada por eles, não para serem expulsos, mas efetivamente para evitarem os assassinatos. Há um jogo de corpo e de linguagem que sinalizam os enfrentamentos. Driblar o mais forte requeria aprendizagem no âmbito das ocasiões decisivas da luta, inventando novas e diferenciadas práticas.

É nesse campo, não se deixando abater pelas investidas do adversário, que os posseiros se organizavam em surdina, multiplicando as ações, planejando emboscadas, armando trincheiras e, sobretudo, invertendo a força do outro, transformando-a em alvo a atingir. É assim que o senhor José Vasconcelos anuncia como foi armado o plano para realizarem uma emboscada decisiva: "Fizeram uma reunião e colocaram o Ari Ventinha como 'isca." Sebastião do Véu explica melhor:

Uns ficam entrincheirado aqui e os outros vai pra lá e funciona a motoserra, do jeito que os pistoleiros chegam e vejam. Quando foi cedinho, os pistoleiros pararam a Toyota, lá escutou o barulho do moto-serra, foi só descendo da Toyota e o fogo comendo...

Neste episódio, morreram dois pistoleiros, um deles no hospital de Porto Alegre do Norte e outro, como aponta Marcos Ramos França, "apareceu morto embaixo de um pé de murici", e ainda mais, a Toyota foi encontrada queimada. Essa vitória dos posseiros foi alardeada pelos quatro cantos do Araguaia, porque também reforçava outras ações de tocaia, emboscadas e confronto armado nos diversos núcleos de assenta- 
mentos. Quando a polícia passou a investigar o crime, os posseiros surpreenderam ainda mais:

Então, os que fizeram o conflito não eram os mesmos daqui, eles deixaram os de fora vierem e fazerem a "coisa" e vazaram para não complicar os daqui. Às vezes têm muitos que fala foi fulano, foi cicrano, mas isto ai é jogo. (Osvaldo Pires)

Ninguém se mostrou responsável, ninguém soube dizer o nome dos envolvidos, ninguém esteve presente. O crime se tornava, na arte da linguagem, anônimo. O senhor Osvaldo Pires detalha a operação:

Ajuntava a parceria de uma área com a outra área e, se caso o conflito era aqui, no PA Canta Galo, às vezes vinha à turma do PA Jacaré Valente, lá também estava em conflito, e outras áreas também vinham para ajudar.

Apareciam onde não eram esperados, ou melhor, como não eram aguardados, na condição de guerreiros. Porém, o jogo fundamental estava em armar uma rede de informações e ações que produziam uma atmosfera de defesa e ataque, especialmente de invisibilidade. Podiam estar, ao mesmo tempo, em todos os lugares e em nenhum, sem lugar próprio não haveria como aprisioná-los: o importante era não se deixar capturar.

Ler a história política, cultural, social do território do Araguaia, os nomes dos lugares, com suas cidades e povoados, suscita inúmeras associações de imagens que conta um pouco da história do Brasil, da marcha de homens e mulheres, assinalada em uma cartografia das migrações. Não há lugar em que homens/mulheres se estabeleçam e não forneçam indícios, signos, segredos possíveis de serem interpretados, ressignificados nas várias histórias relatadas. Pode-se escolher estudar a história do Araguaia examinando cada rosto e gesto de luta, nos múltiplos sinais desses espaços - demarcados em uma geografia do poder - , tendo os relatos orais de memórias como uma das suas trilhas. 


\section{Referências bibliográficas}

ALBERTI, Verena. História Oral: a experiência do CPDOC. Rio de Janeiro: Fundação Getúlio Vargas, 1990.

CALVINO, Ítalo. Jorge Luís Borges. In: Por que ler os clássicos. São Paulo: Cia das Letras, 1993.

CASALDALIGA, Pedro. Uma igreja da Amazônia em conflito com o latifúndio e a marginalizaçãa social. Prelazia de São Félix do Araguaia-MT, 1971.

CERQUEIRA, Maria Figueira. Colonização e conflitos sociais em Confresa. Universidade Federal de Mato Grosso, 2002. (Monografia de conclusão do curso de História).

CERTEAU, Michel de. A operação historiográfica. In. A escrita da história. Rio de Janeiro: Forense-Universitária, 1982.

CHARTIER, Roger. A bistória cultural: entre práticas e representações. Lisboa / Rio de Janeiro: : Difel / Bertrand Brasil, 1990.

ESTERCI, Neide. O conflito no Araguaia: Peões e posseiros contra a Grande Empresa. Petrópolis: Vozes, 1987.

FERREIRA, Marieta de Moraes e AMADO, Janaína. Usos \& abusos da história oral. Rio de Janeiro: Fundação Getúlio Vargas, 1996.

FERREIRA Eudson de Castro, FERNÁNDEZ, Antônio João Castrilon; SILVA, Evande Praxedes da. Os assentamentos em Mato Grosso. In: MEDEIROS, Leonilde Servolo de e LEITE, Sérgio (org.). A formação dos assentamentos rurais no Brasil: processos sociais e políticas públicas. Porto Alegre / Rio de Janeiro: UFRGS / CPDA, 1999, p. 197-231.

GINZBURG, Carlo. Sinais: Raízes de um paradigma indiciário. In: Mitos, Emblemas, Sinais: morfologia e história. São Paulo: Companhia das Letras, 1989.

GUIMARÃES NETO, Regina Beatriz. Vira mundo, vira mundo: trajetórias nômades. As cidades na Amazônia. Projeto História. São Paulo, PUC, n. 27, 2003, p. 49-69.

A lenda do ouro verde: Política de Colonização no Brasil contemporâneo. Cuiabá: Ed. UNICEN, 2002

LE GOFF, Jacques. A história nova. São Paulo: Martins Fontes, 1990.

. Memória-História. In: Enciclopédia Einaudi. Vol. I. Porto: Imprensa Nacional-Casa da Moeda, 1984.

LEVI, Giovani. A herança imaterial: trajetória de um exorcista no Piemonte do século XVII. Rio de Janeiro: Civilização Brasileira, 2000.

Sobre a micro-história. In: BURKE, Peter (org.). A Escrita da História: novas perspectivas. São Paulo: UNESP, 1992.

LIMA, Maria do Rosário Soares. Uma história de luta e resistência entre fazendeiros e sertanejos, no povoado Beira do Rio (Porto Alegre do Norte), décadas de 1960 a 1970. Universidade Federal de Mato Grosso, 2002. (Monografia de conclusão do Curso de História). 
MARTINS, Edilson. Nós, do Araguaia. Rio de Janeiro: Graal, 1979.

MONTENEGRO, Antônio Torres. Rachar as palavras. Ou uma história a contrapelo. História Unisinos. São Leopoldo, Unisinos, v. 09, n. 11, 2006.

História oral e memória: a cultura popular revisitada. São Paulo: Contexto, 1994.

MORENO, Gislaene. Terra e poder em Mato Grosso: políticas e mecanismos de burla - 1892 1992. Cuiabá: EdUFMT, 2007.

OLIVEIRA, Ariovaldo Umbelino de A fronteira amazônica mato-grossense: grilagem, corrupção e violência. São Paulo, FFLCH-USP, 1997. (Tese de Livre Docência em Geografia).

OLIVEIRA, João Mariano. A esperança vem na frente - o caso SINOP. São Paulo, FFLCHUSP, 1982. (Dissertação de Mestrado em História).

REVEL, Jacques (org.). Jogos de escala: a experiência da microanálise. Rio de Janeiro: Fundação Getúlio Vargas, 1998.

RICOEUR, Paul. La mémoire, l’histoire, l'oubli. Paris: Seuil, 2000.

. Tempo e narrativa, tomo I. Campinas: Papirus, 1994.

SANTOS, José Vicente Tavares dos. Matuchos - Exclusão e luta: do Sul para a Amazônia, Petrópolis, Rio de Janeiro: Vozes, 1993.

SOUZA, Maria Aparecida Martins. A Luta pela permanência na terra: A resistência dos Posseiros de Santa Terezinha - década de 1970. Universidade Federal de Mato Grosso, 2002. (Monografia de conclusão do Curso de História)

SOUZA, Edison Antônio de. Sinop: história, imagens e relatos. Um estudo sobre a colonização. Cuiabá: EdUFMT, 2004.

VAINFAS, R. Os protagonistas anônimos da história: micro-bistória. Rio de Janeiro: Campus, 2002.

Resumo: Neste artigo procuro refletir acerca das abordagens teóricas e metodológicas, fundamentais para as investigações que desenvolvo acerca da história de algumas cidades, situadas na parte nordeste de Mato Grosso (território do Araguaia). Privilegio certos aspectos, pequenos acontecimentos, situações vividas, jogos de negociações, conflitos diversos na luta pela posse da terra, num espaço de poder em que se enfrentam agricultores, posseiros e diversos trabalhadores sem terra e grandes proprietários. O interesse é captar nos inúmeros relatos de homens e mulheres os fios condutores para uma análise das práticas sociais e culturais dessas cidades, em que o passado e o presente aparecem tecidos nas urdiduras das memórias, oferecendo um dos acessos possíveis à compreensão do movimento de ocupação e reterritorialização do espaço amazônico, nas três últimas décadas do século XX e inícios do século XXI.

Palavras-chave: colonização; trabalhadores rurais; Araguaia.

Memory, narratives and spaces practices: cities in recent ocupation areas in Amazon (Mato Grosso, 1970-2000)

Abstract: In this paper we discuss some theoretical and methodological approaches for the researches on the history of some cities - located at the north- 
east of Mato Grosso state (Araguaia), working with the small events, the lived situation, the negotiating games and all kinds of conflicts in the fight for land in a space where small and big farmers and landless workers dispute. We aim to reach, in the narratives of men and women, the patterns for the analysis of social and cultural practices in these cities, trying to offer a possible comprehension of the Amazon occupation in the last decades of the 20th century and beginning of the 21 st century.

Keywords: colonization; rural workers; Araguaia. 